\title{
Cancer-Stromal Cell Interaction and Tumor Angiogenesis in Gastric Cancer
}

\author{
Yasuhiko Kitadai
}

Received: 4 October 2009 / Accepted: 10 November 2009 /Published online: 18 December 2009

(C) The Author(s) 2009. This article is published with open access at Springerlink.com

\begin{abstract}
Recent studies in molecular and cellular biology have shown that tumor growth and metastasis are not determined by cancer cells alone but also by a variety of stromal cells. The stroma constitutes a large part of most solid tumors, and cancer-stromal cell interaction contributes functionally to tumor growth and metastasis. Angiogenesis is the result of an imbalance between positive and negative angiogenic factors released by tumor and host cells into the microenvironment of the neoplastic tissue. In gastric cancer, tumor cells and stromal cells produce various angiogenic factors, including vascular endothelial growth factor, interleukin-8, and platelet-derived endothelial cell growth factor. The microenvironment in the gastric mucosa may also influence the angiogenic phenotype of gastric cancer. Helicobacter pylori infection increases expression of several angiogenic factors by tumor cells. Activated fibroblasts and macrophages in tumor stroma also play an important role in angiogenesis and tumor progression. We review the current understanding of cancer-stromal cell interaction as it pertains to tumor angiogenesis in gastric cancer.
\end{abstract}

Keywords Gastric cancer · Angiogenesis · Tumor-stromal cell interaction - Carcinoma-associated fibroblast (CAF) . Tumor-associated fibroblast (TAM) .

Mesenchymal stem cell (MSC)

$\begin{array}{ll}\text { Abbreviations } \\ \text { CAF } & \text { Carcinoma-associated fibroblast } \\ \text { TAM } & \text { Tumor-associated fibroblast }\end{array}$

Y. Kitadai $(\bowtie)$

Department of Medicine and Molecular Science,

Hiroshima University Graduate School of Biomedical Sciences,

1-2-3 Kasumi, Minami-ku,

Hiroshima 734-8551, Japan

e-mail: kitadai@hiroshima-u.ac.jp

$\begin{array}{ll}\text { MSC } & \text { Mesenchymal stem cell } \\ \text { VEGF } & \text { Vascular endothelial growth factor } \\ \text { IL } & \text { Interleukin } \\ \text { FGF } & \text { Fibroblast growth factor } \\ \text { PD-ECGF } & \text { Platelet-derived endothelial cell growth factor } \\ \text { MVD } & \text { Microvessel density } \\ \text { H. pylori } & \text { Helicobacter pylori } \\ \text { COX } & \text { Cyclooxygenase } \\ \text { CagA } & \text { Cytotoxin-associated gene A } \\ \text { NF-kB } & \text { Nuclear factor-kB } \\ \text { MMP } & \text { Matrix metalloproteinase } \\ \text { MCP } & \text { Monocyte chemoattractant protein } \\ \text { TGF } & \text { Transforming growth factor } \\ \text { FAP } & \text { Fibroblast activation protein } \\ \text { EMT } & \text { Epithelial-to-mesenchymal transition }\end{array}$

\section{Introduction}

Cancer tissue consists of both tumor cells and stromal cells, all of which are surrounded by extracellular matrix. Tumor growth is determined not only by tumor cells themselves but also by stromal cells. Recent studies have shown that interactions between tumor and stromal cells create a unique microenvironment that is essential for tumor growth and metastasis [1, 2]. Tumor stroma contains several types of cells including activated fibroblasts (myofibroblasts), endothelial cells, and inflammatory cells including macrophages (Fig. 1). It has become clear that activated fibroblasts in cancer stroma are prominent modifiers of tumor progression. As such, they are called carcinomaassociated fibroblasts (CAFs) [3]. Angiogenesis, which is necessary for tumor progression, is also influenced by the organ microenvironment. Stromal reaction (desmoplasia) is 
Fig. 1 Interaction between gastric cancer cells and stromal cells influences angiogenesis through various angiogenic factors and cytokines. EMT epithelial-to-mesenchymal transition; MSCs mesenchymal stem cells; $E P C s$ endothelial progenitor cells

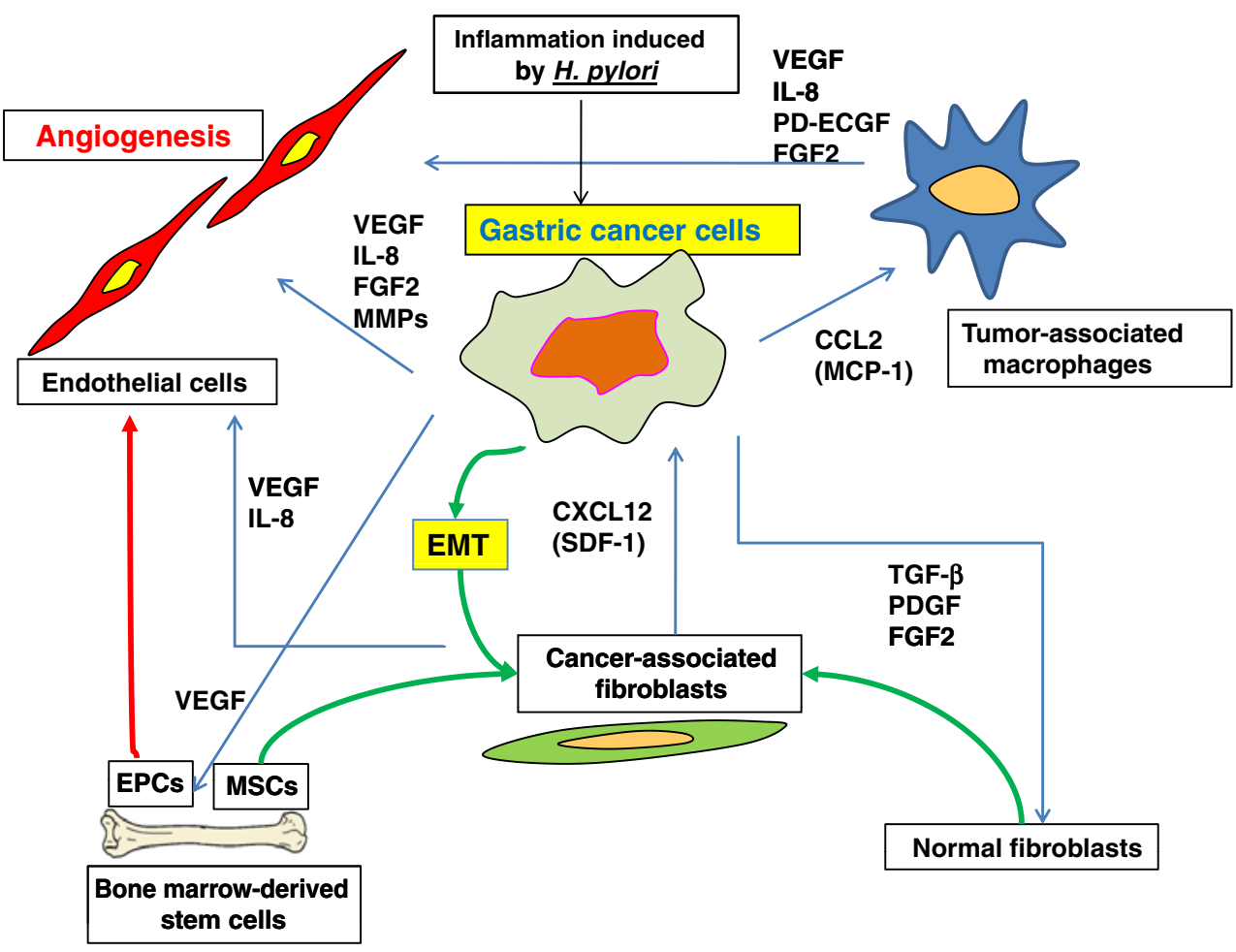

observed in gastrointestinal cancers but not in non-invasive neoplasms [4]. The generation of tumor stroma is triggered by tumor cells and induces the ingrowth of new blood vessels and mesenchymal cells from the adjacent normal tissue [5]. However, recent studies revealed that bone marrow-derived stem cells are integrated into tumor stroma and differentiate into myofibroblasts and vascular endothelial cells $[6,7]$.

Gastric cancer is one of the most frequent malignancies in the world [8]. Previous studies have indicated that a large number of genetic and epigenetic alterations in oncogenes and tumor suppressor genes as well as genetic instability determine the multi-step process of gastric carcinogenesis $[8,9]$. In addition, the molecular events that characterize gastric cancer differ, depending on the histologic type, whether intestinal (well-differentiated) or diffuse (poorly differentiated) gastric cancer [9]. Gastric cancer cells express a wide array of growth factors, angiogenic factors, and cytokines that act via autocrine, paracrine, and juxtacrine mechanisms in the tumor microenvironment [8]. Herein, we discuss the importance of the organ-specific microenvironment and cancer-stromal cell interaction in the growth and angiogenesis of human gastric cancer.

\section{Angiogenic Factors in Human Gastric Cancer}

Weidner et al. [10] first reported a direct correlation between the incidence of metastasis and the number and density of blood vessels in invasive breast cancers. Similar studies have confirmed this correlation in gastrointestinal cancers [11-14]. Induction of angiogenesis is mediated by various molecules released by both tumor and host cells $[15,16]$. Several growth factors that regulate angiogenesis have been identified. Gastric cancer cells produce various angiogenic factors, including vascular endothelial growth factor (VEGF) [13], interleukin (IL)-8 [17], fibroblast growth factor (FGF)-2 [18], and platelet-derived endothelial cell growth factor (PD-ECGF) [19].

Among the various angiogenic factors, VEGF (now termed VEGF-A) is considered one of the strongest promoters of angiogenesis in gastrointestinal tumors [20]. VEGF-A is released by cancer cells, but fibroblasts and inflammatory cells in tumor stroma are also sources of hostderived VEGF-A [21]. VEGF-A, also known as vascular permeability factor, is a secreted protein that plays a pivotal role in hyperpermeability of the vessels in addition to angiogenesis [22]. Several studies have shown a correlation between VEGF-A expression and microvessel density (MVD) in human gastric cancer [13]. The prognosis of patients with VEGF-A-positive tumors is poorer than that of patients with VEGF-A-negative tumors [12, 14].

For gastric cancer, prognosis is dependent on both the histologic type and the disease stage [23]. The intestinaltype gastric cancer tends to metastasize to the liver by hematogenous dissemination. In contrast, the diffuse-type gastric cancer is more invasive; peritoneal dissemination is predominant. We have found that the angiogenic phenotype differs between intestinal-type and diffuse-type gastric cancers [13]. Intestinal-type gastric cancer is more depen- 
dent on angiogenesis than is the diffuse-type. Intestinaltype but not diffuse-type tumors express high levels of VEGF-A, levels of that correlate significantly with vessel counts [13]. In contrast, FGF2 expression is higher in diffuse-type tumors, especially scirrhous-type cancer [18]. These findings suggest that VEGF-A promotes angiogenesis and progression of human gastric cancers, especially those of the intestinal type.

IL-8 is a multi-functional cytokine that can stimulate division of endothelial cells. IL-8 can induce migration of some tumor cells [24] and has been implicated in the induction of angiogenesis in such diverse diseases as psoriasis and rheumatoid arthritis and in some malignant diseases. IL-8 is a known angiogenic factor for human lung cancer $[25,26]$ and is also produced by melanomas [27] and bladder [28] and prostate [29] cancers. In human gastric cancer, most tumor tissues express IL-8 at levels higher than those in the corresponding normal mucosa [17]. The level of IL-8 mRNA in neoplasms correlates strongly with vascularization, suggesting that IL-8 in tumor tissue regulates neovascularization [17]. Furthermore, gastric cancer cells transfected with the IL-8 gene were shown to produce rapidly growing, highly vascular neoplasms at the orthotopic site (gastric wall) in nude mice [30].

PD-ECGF, an endothelial cell mitogen initially purified to homogeneity from human platelets, has chemotactic activity for endothelial cells in vitro and is angiogenic in vivo [31]. PD-ECGF was shown to be identical to thymidine phosphorylase, an enzyme involved in pyrimidine nucleoside metabolism [32]. PD-ECGF expression is elevated in several types of solid tumor including colon cancer [33-35]. PD-ECGF is expressed at high levels in vascular tumors that express low levels of VEGF-A [35]. In these colon cancers, the major source of PD-ECGF is the infiltrating macrophages. A positive association between PDECGF expression and MVD has also been reported for human gastric cancer $[19,36]$. In human gastric cancer, PDECGF is expressed more frequently in infiltrating cells than in tumor epithelium [19]. There is an association between PD-ECGF expression by infiltrating cells, VEGF-A expression by tumor epithelium, and vessel counts in intestinal-type gastric cancer but not in diffuse-type gastric cancer [19].

\section{Lymphangiogenic Factors in Human Gastric Cancer}

VEGF-C and VEGF-D are ligands for VEGF receptor (VEGFR)-3 and VEGFR-2. VEGFR-3 is a tyrosine kinase receptor that is expressed predominantly in the endothelium of lymphatic vessels [37]. Alitalo et al. [38] described VEGF-C as a lymphangiogenic factor that can selectively induce hyperplasia of the lymphatic vasculature. Other growth factors are reported to be lymphangiogenic, such as
FGF-2 [39], platelet-derived growth factor (PDGF)-BB [40], and angiopoietin-2 [41]. VEGF-C/VEGFR-3 signaling is a key primary proliferation pathway for lymphatic vessels, whereas angiopoietin-2 is important in later remodeling stages [41]. Although the importance of FGF2, PDGF-BB, and angiopoietin-2 for lymphatic metastasis of gastric cancer is unknown, a significant correlation between lymph node metastasis and VEGF-C expression has been reported in human gastric cancer [42, 43]. VEGF$\mathrm{C}$ immunoreactivity was associated with lymphatic invasion, lymph node metastasis, and increased MVD, however, there was no association between VEGF-D immunoreactivity and clinicopathologic features in submucosally invasive gastric cancer [44]. These results suggest that VEGF-C is a dominant regulator of lymphangiogenesis in early-stage human gastric cancer.

\section{Helicobacter pylori (H. pylori) Stimulates Angiogenesis in Gastric Cancer}

The most significant advance in understanding the pathogenesis of gastric cancer is recognition of the role of $H$. pylori in gastric carcinogenesis. H. pylori infection is thought to contribute significantly to the pathogenesis of atrophic gastritis and intestinal metaplasia. Epidemiologic studies have indicated that infection with $H$. pylori is a risk factor for gastric cancer, and the WHO/IARC classified this bacterium as a definite biologic carcinogen in 1994 [45]. In addition, H. pylori inoculation into the stomach of Mongolian gerbils was shown to be associated with the occurrence of chronic gastritis, intestinal metaplasia, and adenocarcinoma [46, 47]. There are several virulenceassociated $H$. pylori genes, including cagA, vacA, iceA, and babA [8]. The cagA-positive strains are associated with a higher grade of gastritis and higher risk of gastric cancer than are the cagA-negative strains [48]. The cagA gene is located within the cag pathogenicity island (PAI). The cagPAI encodes components of a type IV secretion system, by which the cagA gene product, $\mathrm{CagA}$, is delivered into gastric epithelial cells. CagA binds Srk homology 2 (SH2) domain-containing tyrosine phosphatase SHP-2 and activates its phosphatase activity. A recent study showed that H. pylori penetrates normal, metaplastic, and neoplastic epithelium to cause a strong immune-inflammatory response and promote gastric carcinogenesis [49].

In addition to its deregulation of SHP-2 by CagA, $H$. pylori is a potent activator of nuclear factor-kB (NF-kB) in gastric epithelial cells. Activation of NF-kB by H. pylori infection induces a variety of cytokines, angiogenic factors, MMPs, and adhesion molecules [50, 51]. We reported previously that $H$. pylori-infected gastric cancer patients have greater tumor vascularity than that of gastric cancer 
patients after $H$. pylori eradication [52], suggesting that $H$. pylori infection influences angiogenesis in gastric cancer. Some studies suggested that the cagA-positive strain of $H$. pylori plays an important role in tissue remodeling, angiogenesis, cancer invasion and metastasis [53-55]. Crabtree et al. [53] reported that H. pylori infection induces IL8 production by gastric epithelium. We found that coculture of gastric cancer cells with $H$. pylori induces expression of mRNAs encoding IL-8, VEGF-A, angiogenin, urokinasetype plasminogen activator, and MMP-9 by gastric cancer cells [54]. Wu et al. [55] also reported that $H$. pylori influences expression of VEGF-A and MMP-9 and promotes gastric cell invasion via COX-2- and NF-kB-mediated pathways. Cox-2 inhibition decreases expression of angiogenic factors and MMP activity [56].

\section{Role of Tumor-Associated Macrophages (TAMs) in Angiogenesis}

Macrophages belonging to the mononuclear phagocyte system exhibit functions in endocytosis and cytotoxicity and secrete more than 100 biologically relevant substances [57]. Macrophages recruited to tumor stroma are called TAMs. The role of TAMs in tumor progression is complicated and wide ranging. Although activated macrophages may have anti-tumor activity, tumor cells have been reported to escape the anti-tumor activity of TAMs [58]. Indeed, removal of macrophages by genetic mutation reduced tumor progression and metastasis [59]. TAMs are recruited from circulating monocytes into tissues in response to chemoattractants, and they interact with tumor cells to make cancer stroma. One important characteristic of macrophages is the potential for angiogenic activity. Activated macrophages produce various factors that induce angiogenesis in wound repair [60], in chronic inflammatory diseases such as rheumatoid arthritis [61] and psoriasis [62], and in atherosclerotic plaques [63]. We previously reported that macrophage infiltration into tumor tissue correlates significantly with tumor vascularity in human esophageal and gastric cancers [64, 65]. Ishigami et al. [66] also found a direct association between the degree of TAM infiltration and depth of tumor invasion, nodal status, and clinical stage in gastric cancer. Macrophage recruitment is mediated by a variety of chemoattractants, including monocyte chemoattractant protein-1 (MCP-1/CCL2), macrophage inflammatory protein $1 \alpha$ (MIP- $1 \alpha / \mathrm{CCL} 3)$, regulated upon activation, normal $\mathrm{T}$ cell expressed and secreted (RANTES/CCL5). Of these CC chemokines, MCP-1 is one of the most potent [67]. We found that MCP-1 produced by tumor cells is associated significantly with macrophage infiltration and malignant behavior, such as angiogenesis, tumor invasion, and lymphatic infiltration $[64,65]$. Trans- fection of the MCP-1 gene into gastric cancer cells causes strong infiltration of macrophages into tumors and enhanced tumorigenicity and metastatic potential in a mouse orthotopic implantation model [68]. Because activated macrophages produce VEGF-A, IL-8, FGF2, and PD-ECGF, MCP-1 expressed by gastric cancer cells plays a role in angiogenesis via recruitment and activation of macrophages.

Cyclooxiganase 2 (COX-2) expressed by cancer and stromal cells has been shown to contribute to tumor angiogenesis [69]. The expression levels of COX-2, in both tumor and stromal cells, correlated well with VEGF levels and MVD in gastric cancer tissue [70]. The CD40 ligand $(\mathrm{CD} 40 \mathrm{~L}) / \mathrm{CD} 40$ interaction has been shown to induce COX-2 expression in macrophages, fibroblasts, and endothelial cells [71, 72]. Furthermore, MCP-1 and CD40L were shown to have a synergistic effect on COX-2 expression and subsequent VEGF production by macrophages in gastric cancer [72].

\section{CAFs Promotes Tumor Growth via Angiogenesis}

It has been reported that normal fibroblasts inhibit progression of cancer. Overexpression of transforming growth factor (TGF)- $\beta$ and hepatocyte growth factor in fibroblasts resulted in tumorigenic outgrowth of breast epithelium, which was inhibited by normal fibroblasts [73]. The inhibition of TGF- $\beta$ signaling in fibroblasts resulted in prostate intraepithelial neoplasia, indicating that normal fibroblasts suppress carcinogenesis [74]. However, numerous studies provided evidence that CAFs indeed promote the growth of tumors $[75,76]$. CAFs show gene expression profiles that are distinct from those of normal fibroblasts [77], and they acquire a modified phenotype, similar to fibroblasts associated with wound healing. Although the mechanisms that regulate activation of fibroblasts and their accumulation in tumors are not fully understood, PDGF, TGF- $\beta$, and FGF2 are known to be partly involved in this process $[75,76,78]$. Many human tumors secrete PDGF ligands and PDGF receptors are expressed by various stromal cell populations such as CAFs and pericytes [7880]. Inhibition of paracrine PDGF signaling reduces stromal reaction and disrupt pericyte support, resulted in destabilizing tumor vasculature and inhibiting angiogenesis [81-83]. In mouse model of cervical cancer, inhibition of stromal PDGFR by imatinib suppressed the expression of FGF-2 (a proangiogenic factor) and FGF-7 (a growth factor for epithelial cell) by CAFs [82]. Recently, we found that PDGF receptor is highly expressed by CAFs, pericytes, and lymphatic endothelial cells in human gastric cancer and targeting PDGF receptor by imatinib inhibited tumor growth and metastasis in the orthotopic gastric cancer model (Sumida et al., unpublished data). Fibroblast activa- 
tion protein (FAP) is expressed by activated fibroblasts during wound healing and within tumor stroma. An antibody to human FAP, sibrotuzumab, is now under clinical study in patients with colorectal cancer and nonsmall cell lung cancer [84]. CAFs might serve as novel therapeutic targets in cancer.

\section{Bone Marrow-derived Mesenchymal Stem Cells (MSCs) as a Source of CAFs}

Although CAFs have been implicated in important aspects of solid tumor biology including tumor growth, angiogenesis, and metastasis, sources of CAFs have not been well defined [85]. There are some candidates for the origins of CAFs, such as fibroblasts residing in local tissues [76], periadventitial cells including pericytes and vascular smooth muscle cells [86], endothelial cells [87], or bone marrow-derived cells including various stem cells [6]. Worthley et al. [88] recently reported that bone marrowderived cells can differentiate CAFs in human gastric cancer that developed in female recipients of male allogeneic stem cell transplantation. Major types of stem cells in the bone marrow are hematopoietic stem cells and MSCs. MSCs can be defined according to their ability to self-renew and differentiate into tissues of mesodermal origin, including bone, cartilage, and adipose and connective tissues [89]. MSCs were reported to migrate to sites of tissue injury, sites of inflammation, as well as to stroma in solid tumor, where they interact with tumor cells [90]. Several studies have implicated molecules such as CXCL12 (SDF-1)/CXCR4, CCL2 (MCP-1)/CCR2, and PDGF in the tumor-homing ability of MSCs [91-93]. In an in vitro experiment, MSCs exposed to tumor-conditioned medium over a prolonged period of time assumed a CAF-like myofibroblastic phenotype, which promotes tumor cell growth both in vitro and in vivo [94]. Banerjee et al. constructed an in vitro model for the tumor-stroma interaction by culturing MSCs exposed to tumorconditioned medium (representing CAFs), tumor cells, and differentiated HL60/U937 cells as surrogates for TAM, and found that the presence of CAFs and TAMs promotes growth of tumor cells. Indeed, CAFs and TAMs actively participate in altering the growth activity and drug resistance of tumors in vivo $[95,96]$. Guo et al. [97] recently constructed a gastric cancer mouse model (Gan mice) by simultaneous activation of prostaglandin E2 and Wnt signaling in the gastric mucosa. MVD increased significantly, and the expression of VEGF-A was predominantly induced in the stromal cells of gastric tumors in the Gan mice. Moreover, they showed by bone marrow transplantation experiments that a subset of gastric myofibroblasts is derived from bone marrow. We examined the role of MSCs in the tumor microenvironment using orthotopic nude mice models of gastric and colon cancers. Systemically administered MSCs possessed the ability to migrate to the orthotopic tumor site, where they differentiate into CAFs. Tumor cells mixed with MSCs and implanted orthotopically resulted in a greater tumor volume and lower survival rate than did implantation of tumor cells alone (Shinagawa et al., unpublished data).

\section{Epithelial-to-Mesenchymal Transition (EMT) as a Source of CAFs}

EMT is conversion of epithelial cells to migratory fibroblastoid cells [98]. Cancer cells undergoing EMT lose epithelial polarity, acquire a spindle-shaped morphology, and develop invasive and migratory ability. In various cancers, EMT is associated with poor histologic differentiation and tumor progression $[99,100]$. Several authors have described the expression patterns of EMT-related genes such as E-cadherin, $\beta$-catenin, S100A4, Snail, Slug, Twist, and SIP1 in gastric cancer [101-103]. Down-regulation of E-cadherin expression and high-level of S1004A expression are associated with peritoneal dissemination, serosal invasion, an infiltrating growth pattern, and a poor prognosis [103]. Up-regulation of Slug, SIP1, and Snail is associated with E-cadherin down-regulation in gastric cancer [101, 102]. Using a tissue array method, Kim et al. [104] examined expression of EMT-related protein in the gastric cancer tissues of 598 patients and found that loss of epithelial proteins and acquisition of mesenchymal proteins are associated with poorly differentiated histology and a poor outcome.

Recent studies revealed that there are genetic alterations that occur at similar frequencies in both cancer cells and surrounding stromal cells $[105,106]$. In addition, a nonrandom X-chromosome-inactivation pattern was found in both stromal fibroblasts and cancer cells in a breast cancer model [107]. Thus, cancer cells and a subset of CAFs might be of the same origin. EMT of cancer cells may also account for CAFs that are present in tumors.

\section{Future Perspectives}

It has been believed that endothelial cells in tumor vessels are genetically stable and that these cells will not become drug resistant in response to antivascular therapy. However, recent studies showed that endothelial cells in certain tumor vessels are aneuploid and express neoplastic markers [108]. Similarly, it has become clear that CAFs in certain tumors have somatic gene alterations. We should elucidate whether genetic and/or epigenetic alterations exist in CAFs and endothelial cells in tumor vessels. 
The different cell types populating the tumor stroma, i.e., CAFs, CAMs, endothelial cells, and pericytes, can help to create an environment permissive of tumor growth, angiogenesis, and invasion. The evidences presented in this Review indicate that stromal cells might serve as novel therapeutic targets in cancer. Targeted therapy that prevents the stromal support of tumor progression might provide a complementary approach to conventional treatments that target the cancer cells themselves. Because most solid tumors have reactive stroma, targeting of stromal cells may have broad clinical implications as a therapeutic strategy. Further understanding the cellular and molecular mechanisms that regulate cancer-stromal cell interaction and inhibition of stromal cell activation may facilitate development of an effective anti-tumor therapy.

Open Access This article is distributed under the terms of the Creative Commons Attribution Noncommercial License which permits any noncommercial use, distribution, and reproduction in any medium, provided the original author(s) and source are credited.

\section{References}

1. Mantovani A, Allavena P, Sica A et al (2008) Cancer-related inflammation. Nature 454:436-444

2. Whiteside TL (2008) The tumor microenvironment and its role in promoting tumor growth. Oncogene 27:5904-5912

3. Mueller MM, Fusenig NE (2004) Friends or foes — bipolar effects of the tumour stroma in cancer. Nat Rev Cancer 4:839-849

4. Hewitt RE, Powe DG, Carter GI et al (1993) Desmoplasia and its relevance to colorectal tumour invasion. Int J Cancer 53:62-69

5. Dvorak HF (1986) Tumors: wounds that do not heal. Similarities between tumor stroma generation and wound healing. N Engl J Med 315:1650-1659

6. Direkze NC, Hodivala-Dilke K, Jeffery R et al (2004) Bone marrow contribution to tumor-associated myofibroblasts and fibroblasts. Cancer Res 64:8492-8495

7. Matsumoto T, Kuroda R, Mifune Y et al (2008) Circulating endothelial/skeletal progenitor cells for bone regeneration and healing. Bone 43:434-439

8. Smith MG, Hold GL, Tahara E et al (2006) Cellular and molecular aspects of gastric cancer. World J Gastroenterol 12:2979-2990

9. Tahara E (2004) Genetic pathways of two types of gastric cancer. IARC Sci Publ 157:327-349

10. Weidner N, Semple JP, Welch WR et al (1991) Tumor angiogenesis and metastasis-correlation in invasive breast carcinoma. N Engl J Med 324:1-8

11. Takahashi Y, Kitadai Y, Bucana CD et al (1995) Expression of vascular endothelial growth factor and its receptor, KDR, correlates with vascularity, metastasis, and proliferation of human colon cancer. Cancer Res 55:3964-3968

12. Tanigawa N, Amaya H, Matsumura M et al (1996) Extent of tumor vascularization correlates with prognosis and hematogenous metastasis in gastric carcinomas. Cancer Res 56:2671-2676

13. Takahashi Y, Cleary KR, Mai M et al (1996) Significance of vessel count and vascular endothelial growth factor and its receptor (KDR) in intestinal-type gastric cancer. Clin Cancer Res 2:1679-1684
14. Maeda K, Chung YS, Ogawa Y et al (1996) Prognostic value of vascular endothelial growth factor expression in gastric carcinoma. Cancer 77:858-863

15. Folkman J (1986) How is blood vessel growth regulated in normal and neoplastic tissue? G.H.A. Clowes memorial Award lecture. Cancer Res 46:467-473

16. Folkman J (1990) What is the evidence that tumors are angiogenesis dependent? J Natl Cancer Inst 82:4-6

17. Kitadai Y, Haruma K, Sumii K et al (1998) Expression of interleukin-8 correlates with vascularity in human gastric carcinomas. Am J Pathol 152:93-100

18. Tanimoto H, Yoshida K, Yokozaki H et al (1991) Expression of basic fibroblast growth factor in human gastric carcinomas. Virchows Arch B Cell Pathol Incl Mol Pathol 61:263-267

19. Takahashi Y, Bucana CD, Akagi Y et al (1998) Significance of platelet-derived endothelial cell growth factor in the angiogenesis of human gastric cancer. Clin Cancer Res 4:429-434

20. Yancopoulos GD, Davis S, Gale NW et al (2000) Vascular-specific growth factors and blood vessel formation. Nature 407:242-248

21. Fukumura D, Xavier R, Sugiura T et al (1998) Tumor induction of VEGF promoter activity in stromal cells. Cell 94:715-725

22. Senger DR, Galli SJ, Dvorak AM et al (1983) Tumor cells secrete a vascular permeability factor that promotes accumulation of ascites fluid. Science 219:983-985

23. Duarte I, Llanos O (1981) Patterns of metastases in intestinal and diffuse types of carcinoma of the stomach. Hum Pathol 12:237242

24. Wang JM, Taraboletti G, Matsushima K et al (1990) Induction of haptotactic migration of melanoma cells by neutrophil activating protein/interleukin-8. Biochem Biophys Res Commun 169:165-170

25. Strieter RM, Polverini PJ, Arenberg DA et al (1995) Role of C$\mathrm{X}-\mathrm{C}$ chemokines as regulators of angiogenesis in lung cancer. $\mathrm{J}$ Leukoc Biol 57:752-762

26. Smith DR, Polverini PJ, Kunkel SL et al (1994) Inhibition of interleukin 8 attenuates angiogenesis in bronchogenic carcinoma. J Exp Med 179:1409-1415

27. Singh RK, Gutman M, Radinsky R et al (1994) Expression of interleukin 8 correlates with the metastatic potential of human melanoma cells in nude mice. Cancer Res 54:3242-3247

28. Tachibana M, Miyakawa A, Nakashima J et al (1997) Constitutive production of multiple cytokines and a human chorionic gonadotrophin beta-subunit by a human bladder cancer cell line (KU-19-19): possible demonstration of totipotential differentiation. Br J Cancer 76:163-174

29. Greene GF, Kitadai Y, Pettaway CA et al (1997) Correlation of metastasis-related gene expression with metastatic potential in human prostate carcinoma cells implanted in nude mice using an in situ messenger RNA hybridization technique. Am J Pathol 150:1571-1582

30. Kitadai Y, Takahashi Y, Haruma K et al (1999) Transfection of interleukin-8 increases angiogenesis and tumorigenesis of human gastric carcinoma cells in nude mice. Br J Cancer 81:647-653

31. Ishikawa F, Miyazono K, Hellman U et al (1989) Identification of angiogenic activity and the cloning and expression of plateletderived endothelial cell growth factor. Nature 338:557-562

32. Moghaddam A, Bicknell R (1992) Expression of platelet-derived endothelial cell growth factor in Escherichia coli and confirmation of its thymidine phosphorylase activity. Biochemistry 31:12141-12146

33. Reynolds K, Farzaneh F, Collins WP et al (1994) Association of ovarian malignancy with expression of platelet-derived endothelial cell growth factor. J Natl Cancer Inst 86:1234-1238

34. Toi M, Inada K, Hoshina $S$ et al (1995) Vascular endothelial growth factor and platelet-derived endothelial cell growth factor are frequently coexpressed in highly vascularized human breast cancer. Clin Cancer Res 1:961-964 
35. Takahashi Y, Bucana CD, Liu W et al (1996) Platelet-derived endothelial cell growth factor in human colon cancer angiogenesis: role of infiltrating cells. J Natl Cancer Inst 88:1146-1151

36. Maeda K, Chung YS, Ogawa Y et al (1996) Thymidine phosphorylase/platelet-derived endothelial cell growth factor expression associated with hepatic metastasis in gastric carcinoma. Br J Cancer 73:884-888

37. Kaipainen A, Korhonen J, Mustonen T et al (1995) Expression of the fms-like tyrosine kinase 4 gene becomes restricted to lymphatic endothelium during development. Proc Natl Acad Sci USA 92:3566-3570

38. Skobe M, Hawighorst T, Jackson DG et al (2001) Induction of tumor lymphangiogenesis by VEGF-C promotes breast cancer metastasis. Nat Med 7:192-198

39. Kubo H, Cao R, Brakenhielm E et al (2002) Blockade of vascular endothelial growth factor receptor-3 signaling inhibits fibroblast growth factor-2-induced lymphangiogenesis in mouse cornea. Proc Natl Acad Sci USA 99:8868-8873

40. Cao R, Bjorndahl MA, Religa P et al (2004) PDGF-BB induces intratumoral lymphangiogenesis and promotes lymphatic metastasis. Cancer Cell 6:333-345

41. Gale NW, Thurston G, Hackett SF et al (2002) Angiopoietin-2 is required for postnatal angiogenesis and lymphatic patterning, and only the latter role is rescued by Angiopoietin-1. Dev Cell 3:411-423

42. Amioka T, Kitadai Y, Tanaka S et al (2002) Vascular endothelial growth factor-C expression predicts lymph node metastasis of human gastric carcinomas invading the submucosa. Eur J Cancer 38:1413-1419

43. Yonemura Y, Endo Y, Fujita H et al (1999) Role of vascular endothelial growth factor $\mathrm{C}$ expression in the development of lymph node metastasis in gastric cancer. Clin Cancer Res 5:1823-1829

44. Onogawa S, Kitadai Y, Amioka $T$ et al (2005) Expression of vascular endothelial growth factor (VEGF)-C and VEGF-D in early gastric carcinoma: correlation with clinicopathological parameters. Cancer Lett 226:85-90

45. (1994) Schistosomes, liver flukes and Helicobacter pylori. IARC Working Group on the Evaluation of Carcinogenic Risks to Humans. Lyon, 7-14 June 1994. IARC Monogr Eval Carcinog Risks Hum, 61, 1-241

46. Watanabe T, Tada M, Nagai H et al (1998) Helicobacter pylori infection induces gastric cancer in mongolian gerbils. Gastroenterology 115:642-648

47. Honda S, Fujioka T, Tokieda M et al (1998) Development of Helicobacter pylori-induced gastric carcinoma in Mongolian gerbils. Cancer Res 58:4255-4259

48. Kuipers EJ, Perez-Perez GI, Meuwissen SG et al (1995) Helicobacter pylori and atrophic gastritis: importance of the cagA status. J Natl Cancer Inst 87:1777-1780

49. Necchi V, Candusso ME, Tava F et al (2007) Intracellular, intercellular, and stromal invasion of gastric mucosa, preneoplastic lesions, and cancer by Helicobacter pylori. Gastroenterology 132:1009-1023

50. Sharma SA, Tummuru MK, Blaser MJ et al (1998) Activation of IL-8 gene expression by Helicobacter pylori is regulated by transcription factor nuclear factor-kappa B in gastric epithelial cells. J Immunol 160:2401-2407

51. Hatz RA, Rieder G, Stolte M et al (1997) Pattern of adhesion molecule expression on vascular endothelium in Helicobacter pylori-associated antral gastritis. Gastroenterology 112:1908-1919

52. Sasaki A, Kitadai Y, Ito M et al (2003) Helicobacter pylori infection influences tumor growth of human gastric carcinomas. Scand J Gastroenterol 38:153-158

53. Crabtree JE, Wyatt JI, Trejdosiewicz LK et al (1994) Interleukin8 expression in Helicobacter pylori infected, normal, and neoplastic gastroduodenal mucosa. J Clin Pathol 47:61-66
54. Kitadai Y, Sasaki A, Ito M et al (2003) Helicobacter pylori infection influences expression of genes related to angiogenesis and invasion in human gastric carcinoma cells. Biochem Biophys Res Commun 311:809-814

55. Wu CY, Wang CJ, Tseng CC et al (2005) Helicobacter pylori promote gastric cancer cells invasion through a NF-kappaB and COX-2-mediated pathway. World J Gastroenterol 11:31973203

56. Church RD, Fleshman JW, McLeod HL (2003) Cyclo-oxygenase 2 inhibition in colorectal cancer therapy. Br J Surg 90:10551067

57. Nathan CF (1987) Secretory products of macrophages. J Clin Invest 79:319-326

58. Lewis CE, Pollard JW (2006) Distinct role of macrophages in different tumor microenvironments. Cancer Res 66:605-612

59. Condeelis J, Pollard JW (2006) Macrophages: obligate partners for tumor cell migration, invasion, and metastasis. Cell 124:263266

60. Leibovich SJ, Wiseman DM (1988) Macrophages, wound repair and angiogenesis. Prog Clin Biol Res 266:131-145

61. Koch AE, Polverini PJ, Leibovich SJ (1986) Stimulation of neovascularization by human rheumatoid synovial tissue macrophages. Arthritis Rheum 29:471-479

62. Wolf JE Jr (1989) Angiogenesis in normal and psoriatic skin. Lab Invest 61:139-142

63. Sueishi K, Yasunaga C, Castellanos E et al (1990) Sustained arterial injury and progression of atherosclerosis. Ann N Y Acad Sci 598:223-231

64. Ohta M, Kitadai Y, Tanaka S et al (2002) Monocyte chemoattractant protein-1 expression correlates with macrophage infiltration and tumor vascularity in human esophageal squamous cell carcinomas. Int J Cancer 102:220-224

65. Ohta M, Kitadai Y, Tanaka S et al (2003) Monocyte chemoattractant protein-1 expression correlates with macrophage infiltration and tumor vascularity in human gastric carcinomas. Int J Oncol 22:773-778

66. Ishigami S, Natsugoe S, Tokuda K et al (2003) Tumor-associated macrophage (TAM) infiltration in gastric cancer. Anticancer Res 23:4079-4083

67. Fuentes ME, Durham SK, Swerdel MR et al (1995) Controlled recruitment of monocytes and macrophages to specific organs through transgenic expression of monocyte chemoattractant protein-1. J Immunol 155:5769-5776

68. Kuroda T, Kitadai Y, Tanaka S et al (2005) Monocyte chemoattractant protein-1 transfection induces angiogenesis and tumorigenesis of gastric carcinoma in nude mice via macrophage recruitment. Clin Cancer Res 11:7629-7636

69. Mizuno H, Sakamoto C, Matsuda K et al (1997) Induction of cyclooxygenase 2 in gastric mucosal lesions and its inhibition by the specific antagonist delays healing in mice. Gastroenterology 112:387-397

70. Tatsuguchi A, Matsui K, Shinji Y et al (2004) Cyclooxygenase-2 expression correlates with angiogenesis and apoptosis in gastric cancer tissue. Hum Pathol 35:488-495

71. Zhang Y, Cao HJ, Graf B et al (1998) CD40 engagement upregulates cyclooxygenase-2 expression and prostaglandin E2 production in human lung fibroblasts. J Immunol 160:10531057

72. Futagami S, Tatsuguchi A, Hiratsuka T et al (2008) Monocyte chemoattractant protein 1 and CD40 ligation have a synergistic effect on vascular endothelial growth factor production through cyclooxygenase 2 upregulation in gastric cancer. J Gastroenterol 43:216-224

73. Kuperwasser C, Chavarria T, Wu M et al (2004) Reconstruction of functionally normal and malignant human breast tissues in mice. Proc Natl Acad Sci USA 101:4966-4971 
74. Bhowmick NA, Chytil A, Plieth D et al (2004) TGF-beta signaling in fibroblasts modulates the oncogenic potential of adjacent epithelia. Science 303:848-851

75. Orimo A, Gupta PB, Sgroi DC et al (2005) Stromal fibroblasts present in invasive human breast carcinomas promote tumor growth and angiogenesis through elevated SDF-1/CXCL12 secretion. Cell 121:335-348

76. De Wever O, Mareel M (2003) Role of tissue stroma in cancer cell invasion. J Pathol 200:429-447

77. Allinen M, Beroukhim R, Cai L et al (2004) Molecular characterization of the tumor microenvironment in breast cancer. Cancer Cell 6:17-32

78. Pietras K, Sjoblom T, Rubin K et al (2003) PDGF receptors as cancer drug targets. Cancer Cell 3:439-443

79. Anderberg C, Li H, Fredriksson L et al (2009) Paracrine signaling by platelet-derived growth factor-CC promotes tumor growth by recruitment of cancer-associated fibroblasts. Cancer Res 69:369-378

80. Kitadai Y, Sasaki T, Kuwai T et al (2006) Expression of activated platelet-derived growth factor receptor in stromal cells of human colon carcinomas is associated with metastatic potential. Int $\mathbf{J}$ Cancer 119:2567-2574

81. Pietras K, Hanahan D (2005) A multitargeted, metronomic, and maximum-tolerated dose "chemo-switch" regimen is antiangiogenic, producing objective responses and survival benefit in a mouse model of cancer. J Clin Oncol 23:939-952

82. Pietras K, Pahler J, Bergers G et al (2008) Functions of paracrine PDGF signaling in the proangiogenic tumor stroma revealed by pharmacological targeting. PLoS Med 5:e19

83. Kitadai Y, Sasaki T, Kuwai $T$ et al (2006) Targeting the expression of platelet-derived growth factor receptor by reactive stroma inhibits growth and metastasis of human colon carcinoma. Am J Pathol 169:2054-2065

84. Scott AM, Wiseman G, Welt S et al (2003) A Phase I doseescalation study of sibrotuzumab in patients with advanced or metastatic fibroblast activation protein-positive cancer. Clin Cancer Res 9:1639-1647

85. Anderberg C, Pietras K (2009) On the origin of cancerassociated fibroblasts. Cell Cycle 8:1461-1462

86. Kalluri R, Zeisberg M (2006) Fibroblasts in cancer. Nat Rev Cancer 6:392-401

87. Zeisberg EM, Potenta S, Xie L et al (2007) Discovery of endothelial to mesenchymal transition as a source for carcinomaassociated fibroblasts. Cancer Res 67:10123-10128

88. Worthley DL, Ruszkiewicz A, Davies R et al (2009) Human gastrointestinal neoplasia-associated myofibroblasts can develop from bone marrow-derived cells following allogeneic stem cell transplantation. Stem Cells 27:1463-1468

89. Pittenger MF, Mackay AM, Beck SC et al (1999) Multilineage potential of adult human mesenchymal stem cells. Science 284:143-147

90. Studeny M, Marini FC, Dembinski JL et al (2004) Mesenchymal stem cells: potential precursors for tumor stroma and targeted-delivery vehicles for anticancer agents. J Natl Cancer Inst 96:1593-1603

91. Menon LG, Picinich S, Koneru R et al (2007) Differential gene expression associated with migration of mesenchymal stem cells to conditioned medium from tumor cells or bone marrow cells. Stem Cells 25:520-528

92. Dwyer RM, Potter-Beirne SM, Harrington KA et al (2007) Monocyte chemotactic protein-1 secreted by primary breast tumors stimulates migration of mesenchymal stem cells. Clin Cancer Res 13:5020-5027

93. Beckermann BM, Kallifatidis G, Groth A et al (2008) VEGF expression by mesenchymal stem cells contributes to angiogenesis in pancreatic carcinoma. Br J Cancer 99:622-631

94. Mishra PJ, Mishra PJ, Humeniuk R et al (2008) Carcinomaassociated fibroblast-like differentiation of human mesenchymal stem cells. Cancer Res 68:4331-4339

95. Iwamoto S, Mihara K, Downing JR et al (2007) Mesenchymal cells regulate the response of acute lymphoblastic leukemia cells to asparaginase. J Clin Invest 117:1049-1057

96. Mantovani A, Schioppa T, Porta C et al (2006) Role of tumorassociated macrophages in tumor progression and invasion. Cancer Metastasis Rev 25:315-322

97. Guo X, Oshima H, Kitmura T et al (2008) Stromal fibroblasts activated by tumor cells promote angiogenesis in mouse gastric cancer. J Biol Chem 283:19864-19871

98. Hay ED (1995) An overview of epithelio-mesenchymal transformation. Acta Anat (Basel) 154:8-20

99. Thiery JP (2002) Epithelial-mesenchymal transitions in tumour progression. Nat Rev Cancer 2:442-454

100. Brabletz T, Jung A, Spaderna S et al (2005) Opinion: migrating cancer stem cells - an integrated concept of malignant tumour progression. Nat Rev Cancer 5:744-749

101. Rosivatz E, Becker I, Specht K et al (2002) Differential expression of the epithelial-mesenchymal transition regulators snail, SIP1, and twist in gastric cancer. Am J Pathol 161:18811891

102. Castro Alves C, Rosivatz E, Schott C et al (2007) Slug is overexpressed in gastric carcinomas and may act synergistically with SIP1 and Snail in the down-regulation of E-cadherin. J Pathol 211:507-515

103. Yonemura Y, Endou Y, Kimura K et al (2000) Inverse expression of S100A4 and E-cadherin is associated with metastatic potential in gastric cancer. Clin Cancer Res 6:4234-4242

104. Kim MA, Lee HS, Lee HE et al (2009) Prognostic importance of epithelial-mesenchymal transition-related protein expression in gastric carcinoma. Histopathology 54:442-451

105. Fukino K, Shen L, Matsumoto S et al (2004) Combined total genome loss of heterozygosity scan of breast cancer stroma and epithelium reveals multiplicity of stromal targets. Cancer Res 64:7231-7236

106. Kurose K, Gilley K, Matsumoto S et al (2002) Frequent somatic mutations in PTEN and TP53 are mutually exclusive in the stroma of breast carcinomas. Nat Genet 32:355-357

107. Petersen OW, Nielsen HL, Gudjonsson T et al (2003) Epithelial to mesenchymal transition in human breast cancer can provide a nonmalignant stroma. Am J Pathol 162:391-402

108. Streubel B, Chott A, Huber D et al (2004) Lymphoma-specific genetic aberrations in microvascular endothelial cells in B-cell lymphomas. N Engl J Med 351:250-259 